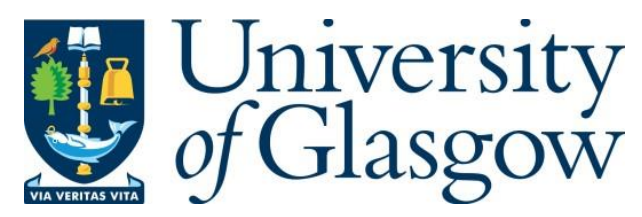

Gooding, P., Smith, J. and Mann, J. (2019) The forensic imagination: interdisciplinary approaches to tracing creativity in writers' born-digital archives. Archives and Manuscripts, 47(3), pp. 374-390.

There may be differences between this version and the published version. You are advised to consult the publisher's version if you wish to cite from it.

http://eprints.gla.ac.uk/184018/

Deposited on: 16 April 2019

Enlighten - Research publications by members of the University of Glasgow http://eprints.gla.ac.uk 
This is an accepted manuscript of an article published by Taylor \& Francis in Archives and Manuscripts on 12/8/2019, available online:

https://www.tandfonline.com/10.1080/01576895.2019.1608837.

\title{
The Forensic Imagination: Interdisciplinary Approaches to Tracing Creativity in Writers' Born-Digital Archives
}

\author{
Paul Gooding ${ }^{\mathrm{a}^{*}}$, Jos Smith ${ }^{\mathrm{b}}$ and Justine Mann ${ }^{\mathrm{c}}$ \\ ${ }^{a}$ Information Studies, University of Glasgow, United Kingdom; ${ }^{b}$ School of Literature, Drama \\ and Creative Writing, University of East Anglia, United Kingdom; 'British Archive for \\ Contemporary Writing, University of East Anglia, United Kingdom.
}

Corresponding address: Dr. Paul Gooding, Information Studies, 11 University Gardens, Email: paul.gooding@glasgow.ac.uk

\section{Abstract}

In 2013, Matthew Kirschenbaum advocated for increased collaboration between digital archivists and digital humanities specialists to make the most out of borndigital archives. Since then, researchers and archivists have experimented with innovative interfaces for access to writer's archives that emerge from individual research cultures and practices. Simultaneously, archives such as the British Archive for Contemporary Writing at the University of East Anglia are beginning to collect the work of authors who work in inventive digital ways. This article will therefore explore the following question: how might archivists, authors, and researchers profitably collaborate to explore the nature of creativity in the borndigital archive, so that both digital preservation and digital scholarship take place? In doing so, we look to the complementary fields of genetic criticism and digital humanities to inform the development of archival tools as 'hermeneutical instruments.' We will explore how such instruments might allow us to read horizontally across archival strata, building on an 'esthetic of the possible' to develop a 'jouer avec les fonds,' supported through collaboration between researchers, archivists and writers. Finally, we consider how this approach challenges archival practices, and propose forms of collaboration that might address both archival practice and emerging forms of scholarship.

Keywords: literary archives; creativity; archiving. 
This is an accepted manuscript of an article published by Taylor \& Francis in Archives and Manuscripts on 12/8/2019, available online:

https://www.tandfonline.com/10.1080/01576895.2019.1608837.

\section{The Forensic Imagination: Interdisciplinary Approaches to Tracing Creativity in Writers' Born-Digital Archives}

\section{Introduction}

In her introduction to The Boundaries of the Literary Archive, Lisa Stead argues that the twenty-first century archive is 'bounded by two insistent, and often seemingly opposing, claims on preservation and the ways we make use of materials'. ${ }^{1}$ On one side there is 'the physicality of the original archival document'; on the other there are 'the virtual qualities of the digitised, and increasingly, born-digital content' ${ }^{2}$ Considerable research has been undertaken on this first physical 'boundary' and the way in which it has shaped both the creativity of authorial work and the inquiries of researchers. The qualities of the born-digital archive are less well explored, despite the fact that the processes for writing, sharing, and disseminating published creative works have come to be increasingly undertaken and informed by computing. From the variety of software programs on PCs and tablet computers, through forms of communication such as Skype, email, and social media, to the production workflows of the publishing industry, an extraordinary heterogeneity has come to characterise the digital archive and its extent is not as clearly demarcated as we might immediately assume. In the following paper we begin to probe this second of these 'boundaries', treating it, in fact, much more like a horizon than a boundary at all. Where boundary suggests a decisive limitation, we set out to recast this extension in terms of the opportunities it may be understood to afford, for authors, for archivists and for researchers too.

In archival terms, the digital traces of the creative process could be viewed as 'just another form of material' to be managed. ${ }^{3}$ Simultaneously, though, the implications for researchers and archivists go far beyond this to challenge how we understand the nature of the archival as a source for interpreting creative works: creation, archiving, and use are all fundamentally transformed through digital technologies. The challenge is not confined solely to the archivist's practice, though, as it has far reaching implications for the ways that researchers in the arts and humanities engage with evidentiary sources in the archive. Our titular reference to the 'forensic imagination' borrows from Matthew Kirschenbaum, who conceives it as a 'deeply humanistic way of knowing, one that assigns value to time, history, 
This is an accepted manuscript of an article published by Taylor \& Francis in Archives and Manuscripts on 12/8/2019, available online:

https://www.tandfonline.com/10.1080/01576895.2019.1608837.

and social or material circumstance - even trauma and wear - as part of our thinking about new media' ${ }^{4}$ The multifaceted nature of these changes has seen researchers call for increased collaboration between archivists and digital humanities specialists to make the most out of born-digital archives. ${ }^{5}$ Concurrently, the emergence of theories of 'humanistic interface design' have sought to engage with the ways that humanities scholars might contribute to the development of innovative tools for presenting and investigating digital archival materials. ${ }^{6}$

This work, however, is situated across several disciplines, and the pluralistic epistemologies of the humanities act as an oppositional force against the archival need to establish standards, best practice, and replicable workflows for their collections. Thus, while researchers wrestle with how best to take advantage of writers' digital archives, the archival community is faced with balancing competing priorities of, on the one hand, safeguarding, preserving and processing their collections, and on the other, providing guidance and access to the scholarly community. The British Archive for Contemporary Writing (BACW) at the University of East Anglia (UEA) provides the context for our work as it begins to collect the work of emerging and established and contemporary novelists, several of whom engage with digital technologies in inventive ways. It is keen to grow its collections with a particular focus on how archivists might best safeguard, investigate, and organise these digital archives to best facilitate future user needs. This article will therefore explore the following question: how might archivists, authors and researchers profitably collaborate to explore the nature of creativity in the born-digital archive, so that both digital preservation and digital scholarship both take place in the most fruitful ways?

To achieve this, we will first introduce the BACW, which holds diverse archival collections from contemporary authors. We will relate the specific challenges faced by the BACW to the task of balancing essential archival practices such as selection, appraisal, processing, and facilitating access, with new directions in scholarship and shifting regulatory and technical environments. The following section introduces the work of BACW authors Naomi Alderman and Richard Beard, in order to examine how creative practices intersect with digital technologies and redefine the extent of the literary archive. We then look to three overlapping domains in order to address how they are responding to the diverse, networked nature of the digital literary archive: literary theory; the digital humanities; and archival theory and practice. We will argue that there is a productive connection between the investigative 'play' of poststructural textuality as it has been put to work in the field of 
This is an accepted manuscript of an article published by Taylor \& Francis in Archives and Manuscripts on 12/8/2019, available online:

https://www.tandfonline.com/10.1080/01576895.2019.1608837.

'genetic criticism', and the humanistic theories of 'building' that emerge from the digital humanities. A resultant approach to archival tools as 'hermeneutical instruments' ${ }^{7}$ could allow us to develop tools that facilitate an 'esthetic of the possible' by allowing us to read horizontally across the archival surface in ways that probe those opportunities at the new limits of the digital archive. ${ }^{8}$ Genetic criticism has resisted the idea of archival work as granting access to any sense of authenticity that might be captured by a 'depth'. Its emphasis on horizontality is a way of suggesting possibility. Complemented by building tools using digital humanities methods we hope to go beyond suggestion towards new forms of facilitation.

However, we will also note that this epistemologically-driven approach to digital archives, with its plurality of interpretations, needs grounding within the archival in its most pragmatic sense to be effective; that is, grounding within the regulations, ethics and practices of institutions that preserve writers' archives, and the variety of methodologies that inform their reuse. The concept of 'respect des fonds,' translated as respect for the fonds, is a foundational one for the arrangement and description of modern archives. It proposes that archives should be organised according to their fonds; groupings of records by the originating organisation, individual, or creating body. Among archivists this principle, taken in its narrowest sense, concerns the duty of care to maintain the completeness and original order of a given author's archive. ${ }^{9}$ However, in an essay on the paper archive of Canadian author and artist Douglas Coupland, Jennifer Douglas demonstrates the difficulties of reconciling the needs of the institution with the respect for that original order, unpicking some of the assumptions that are made by archivists about that original order of the archive, while simultaneously evaluating the 'added value' that comes with institutional intervention. ${ }^{10}$ Far from providing any easy solutions, she opens up an exceptionally intricate terrain which, in the end, sees the myth of the author as original creator recede and the layers of story about the many accumulations of different orders accrue and become significantly more visible. ${ }^{11}$

Building on this within the horizon of the digital archive, we propose the need to codesign archives, and even potentially archival software at the point of archiving, and to codevelop tools for digital forensic work that would allow multiple modes of ordering and interpreting while also, and at the same time, securing the collections that underpin this innovative work. This approach can extend archival practice to encompass a form of what somewhat flippantly - might be described as 'jouer avec les fonds'. We will argue that this 
This is an accepted manuscript of an article published by Taylor \& Francis in Archives and Manuscripts on 12/8/2019, available online:

https://www.tandfonline.com/10.1080/01576895.2019.1608837.

mode of archival research, roughly translated as 'playing with the fonds,' can be uniquely supported by digital archival tools. A digital archive affords forms of keyword searchability, cross referencing, pattern recognition, time coding, restructuring and the support of 'multiple views' without threatening the integrity of any original order and that would simply be impossible with a paper archive. This may be developed to accommodate various and varying institutional requirements at the same time as responding to researchers' creative methodologies, balancing the two in complex ways. Such archival 'play' with the original order might even suggest the possibility of multiple possible orders that each reflect different approaches to - different ways of framing and entering - the archive.

\section{Literary Archives in Context: The British Archive for Contemporary Writing}

The British Archive for Contemporary Writing provides an institutional context for our discussion. ${ }^{12}$ It was launched at UEA in 2015, with collections from Nobel laureates Doris Lessing and Nadine Gordimer, as well as materials from J.D. Salinger. More recently, it has acquired collections from prize-winning alumni of UEA and other acclaimed writers, such as Snoo Wilson, Naomi Alderman, Tash Aw, and Adam Foulds. It also possesses a nature writing collection with the archives of Mark Cocker and Roger Deakin, and a growing collection of crime writing, including the archive of Lee Child, and comedy writing including television scripts from notable UK-based comedians like Charlie Higson. ${ }^{13}$ The latest collections to be accessioned have been 'hybrid,' in the sense that they contain both print and digital materials. In common with other archives, though, anecdotal reports suggest a significant reduction in the proportion of accessioned material that is in print format.

A key catalyst for the creation of the BACW was the 'loss' of writers' archives to overseas institutions. Many literary archives are sold overseas to US institutions and like other archives in UK National Libraries and UK Higher Education institutions, UEA is unable to compete with the vast sums paid. ${ }^{14}$ In response, the BACW has employed a highly innovative 'storehouse' model that 'enables contemporary writers to house their emerging archives at UEA on a temporary basis' ${ }^{15}$ This allows the collection to be accessed for research and teaching, while providing benefits to the author including professional cataloguing and preservation of their archive that will add value in the event that it is removed. The idea that an author can remove their archive in the future is somewhat alien to traditional archival practice, and thus the BACW must explore ways to ensure institutional 
This is an accepted manuscript of an article published by Taylor \& Francis in Archives and Manuscripts on 12/8/2019, available online:

https://www.tandfonline.com/10.1080/01576895.2019.1608837.

returns from research, teaching and promotion of the university's mission. The collections are thereby available to the university, and the wider scholarly community. They are used for undergraduate and postgraduate teaching in a range of modules, and there is an increased interest from postgraduate researchers, postdoctoral applicants, and researchers developing grants. Visits to the archive have increased by $50 \%$ each year since the BACW was launched, and more than 450 students have participated in archive seminars involving collections that link to their studies.

These are just some of the reasons that the BACW represents a huge opportunity for UEA to build on its literary and creative writing history. Aside from the many and varied opportunities to unlock BACW collections through research and teaching, collaboration with researchers may also allow the development of innovative digital humanities tools to harness the changing affordances of collections in digital formats. The opportunity arises from the significant gaps that exist in our understanding of how to harness writers' digital archival materials for researchers. If we think about materials solely in terms of digital preservation we may miss key opportunities to address emerging research needs. Indeed, in many respects, archival thinking has moved on from digital preservation towards processing, ${ }^{16}$ and in some cases, making available, the author's digital archive. ${ }^{17}$ Emory University Libraries, for instance, experimented with the 'emulation' of Salman Rushdie's desktop computer. ${ }^{18}$ An emulator is software that mimics the behaviour of another computer environment to allow users to access software and files in their native environment. However, this process of recreating author's digital environment at a given moment, cleansed of personal information - embeds a limited explication of the canonical author's lived experience that fails to embrace alternative interpretive frameworks.

This is not a failure of imagination on the part of the archival community, so much as a process of active experimentation within certain boundaries; indeed, as Dorothy Waugh, Elizabeth Russey Roke and Erika Farr make clear, Emory's experience with the Rushdie archive provided an important learning opportunity that has since informed workflows for processing born-digital materials. ${ }^{19}$ Rather, archivists are forced to consider the new horizons of digital records while simultaneously facing the traditional archival challenges of appraising, processing, and facilitating access where possible. For instance, the need for sensitivity reviews is made complex by the large scale and disordered nature of many personal digital archives. Victoria Sloyan, for instance, has documented the challenge faced 
This is an accepted manuscript of an article published by Taylor \& Francis in Archives and Manuscripts on 12/8/2019, available online:

https://www.tandfonline.com/10.1080/01576895.2019.1608837.

by archivists in undertaking a sensitivity review of born-digital material. She notes that digital appraisal tools such as $\mathrm{DROID}^{20}$ can help archivists to meet their legal and moral responsibilities to ensure that sensitive information is not released into the public domain. ${ }^{21}$ This allows archivists to identify file types for further review, but there is neither an automated way to review files for sensitive information, nor a consensus within the archival community about how to process born-digital records. Sloyan, for instance, argues that 'digital appraisal is no different to paper appraisal in that it is underpinned by the same archival theory'. ${ }^{22}$ Terry Cook, on the other hand, has argued for a radical rethinking of archival practice whereby nothing is appraised, and discovery and retrieval is achieved through search engines, archival description and metadata. ${ }^{23}$

The storehouse model adopted at UEA necessarily pushes the BACW to the forefront of thinking about immediate reuse of digital materials, but the challenges that arise are widely applicable to a sector whose practices are developing in response to the need to deal with digital materials of living or recently deceased authors. ${ }^{24}$ In 2013, Matthew Kirschenbaum responded to this problem with a call for increased collaboration between digital archivists and $\mathrm{DH}$ researchers to make the most out of born-digital archives. Kirschenbaum noted that:

The massive challenges facing the professional custodians of history, science, government and cultural heritage in the roughly three and a half decades since the advent of personal computing have been left largely unengaged by the digital humanities. $^{25}$

By drawing attention to this failure of interdisciplinarity, his words seem to remind us of warnings that archivists are often relegated to a role as the 'handmaidens of historians' ${ }^{26}$ Michelle Caswell goes further still, noting that there is a distinct gap between the topics addressed in the humanities and archival studies. The humanities, she argues, are concerned with theorising 'the archive' through Foucualt's systems, or Derrida's death drive, while those in archival studies focus instead upon understanding those institutions, places, materials, and processes that are designated 'archival.' Caswell argues that these two discussions 'are happening on parallel track in which scholars in both disciplines are largely not taking part in the same conversations, not speaking the same conceptual languages, and not benefiting from each other's insights'. ${ }^{27}$ This is not to say that nothing has happened, and indeed Kirschenbaum's call to action has borne fruit as researchers have experimented with 
This is an accepted manuscript of an article published by Taylor \& Francis in Archives and Manuscripts on 12/8/2019, available online:

https://www.tandfonline.com/10.1080/01576895.2019.1608837.

innovative computational approaches to digital archives. Much work has been done to address how interfaces, which can be understood as mediating spaces that create our experience of materials, ${ }^{28}$ are able to support varied approaches to writers' archives: from presenting writers' drafts as a 'transcription mashup' that juxtaposes texts alongside textual variants and drafts on a single screen, ${ }^{29}$ through to creating emulations of Salman Rushdie's personal computer. ${ }^{30} \mathrm{We}$ are interested in building on these interventions to address how collaboration between researchers and archivists can move beyond this process of 'humanistic interface design' ${ }^{31}$ towards an interdisciplinary collaborative model that additionally encompasses archival theory and practice to develop digital tools and methodologies for forensic analysis of writers' archives.

The slow pace of change in the archival sector should not be mistaken for conservatism, but instead needs to be understood in relation to the technical, regulatory, and ethical frameworks that archivists work within. However, we must also consider whether the solutions that have been proposed are truly capturing the creative process, or indeed providing the end user with an adequate experience. The Wellcome Library's approach to sensitivity review excavates everything on the hard drive and makes accessible that which it can through the application of clearly defined risk categories, ${ }^{32}$ yet the boundaries of the archive extend no further than the creator's hard drives. Similarly, the British Library has worked hard to make content available from its Wendy Cope Archive, developing a workflow for processing and providing access to born-digital materials. ${ }^{33}$ Its access model, though, is inspired by a print-era perspective on the usability of archival materials. Typescript materials are available only as PDF/As, within the BL Asian and African Studies Reading Room. The PDF/As can be viewed only via computer terminals in the reading room, and cannot be edited, saved, or printed. Thus, the end result for the user barely advances upon the affordances provided by research with physical archival collections. By contrast, Jane Winters has noted that researchers have an 'increased expectation not just of open access to data but that there will be APIs which allow researchers to download and take away the material with which they choose to work'. ${ }^{34}$

It is essential to address both sides of this conceptual divide to create effective interdisciplinary collaborations that begin to unpack the overlapping challenges of understanding creation, archiving, and reuse of writers' digital archives. The challenge, then, is twofold: first, we must address how writers' archives can be ingested and presented to 
This is an accepted manuscript of an article published by Taylor \& Francis in Archives and Manuscripts on 12/8/2019, available online:

https://www.tandfonline.com/10.1080/01576895.2019.1608837.

researchers in order to support humanistic ways of working; and second, we must understand how this aim can be achieved while respecting the author's intentions for their archive, and ensuring that digital preservation takes place. However, we may also involve all three parties in discussions of what new hermeneutic opportunities are emerging on the digital horizon, assuming that all three parties will see the archive materials in a slightly different light. We will explore how genetic criticism may approach these materials, and demonstrate how this can inform our conceptions of 'building' in the digital humanities to address these challenges. ${ }^{35}$ Existing approaches to archiving and digital preservation continue to promise much in supporting the work of the archivist, but interdisciplinary collaboration can allow us to identify the ways in which digital archives challenge and augment traditional practices in both communities.

\section{'Playing' with the Possibilities of the Digital Archive}

The archival community is thereby wrestling with the challenge of how to curate and present writers' archives to the reader, even as the hybrid nature of archives makes the idea of the 'digital archivist' as a distinct role problematic. Yet the implications of digital archives go beyond the materials, and begin to redefine how we understand the 'archive-as-subject'. ${ }^{36}$ Writers' working practices are changing in response to digital technologies, and this in turn redefines the boundaries of their archive; the way that the traces of their work are found in different systems, with different rights, dependencies, audiences, and data protection implications. The work of Naomi Alderman and Richard Beard, contemporary authors that have loaned their collections to the BACW, emphasises the diversity of the resultant archives. Naomi Alderman is a graduate of the UEA MA in Creative Writing, and prize-winning author of novels and short stories. In 2017, she won the Bailey's Prize for Women's Fiction for The Power, a feminist and dystopian science fiction novel. Alderman is also a journalist, games writer and broadcaster. Her archive is on loan to the BACW, and includes the first draft of The Power. ${ }^{37}$ The draft, taken in isolation, is a single Microsoft Word document. In reality, though, it represents the culmination of an earlier creative process into its first crystallised form, with traces scattered across her electronic devices, her social media accounts, her communications platforms; in other words, her archival footprint. The Disaporic Literary Archives Network ${ }^{38}$ advises that 'all the raw material relating to writer's life is likely to be of interest to an archive service and to researchers' ${ }^{39}$ If we view 
This is an accepted manuscript of an article published by Taylor \& Francis in Archives and Manuscripts on 12/8/2019, available online:

https://www.tandfonline.com/10.1080/01576895.2019.1608837.

Alderman's work, or look at outlines of other writers' creative processes, we can begin to realise the sheer breadth and diversity of this raw material in the context of a digital footprint. However, these traces are already being lost precisely because they are not immediately and obviously associated with the first draft of a specific work. Alderman, for instance, reported that many hours of Skype conversations with her editor had been deleted by Skype. That the writer's digital archive is partial is no surprise, and nor does print offer comprehensiveness, but the diffuse and heterogeneous nature of a writer's digital footprint means that it is particularly complex to address what of Alderman's archive may be lost and what new opportunities it might afford.

Figure 1: Richard Beard's Creative Process

The hybrid nature of the writer's archive is demonstrated in Figure 1, which outlines the English novelist Richard Beard's creative process. Beard, who has deposited materials with the BACW, is an English novelist, non-fiction writer and Creative Writing Fellow at UEA. He has published six novels with Vintage including Acts of the Assassins (2015) which was short-listed for the Goldsmiths Prize. ${ }^{40}$ His non-fiction works encompass topics including rugby, competitiveness in Australia, and the gender reassignment of a close friend. The BACW took possession of Beard's archive on loan in 2016, in a mix of analogue and digital formats. His creative process demonstrates the complex material and interpersonal networks that encompass creativity._Beard, much like many writers who still value hand writing for its ability to slow down their thought process, starts writing in notebooks. ${ }^{41}$ These contain structural diagrams, character sketches, and chapter outlines. The notes evolve into a typescript, with the entries in the notebook ticked off like a to-do list as the first draft begins to take shape. Drafts are then printed and annotated, before these annotations are subsumed into the next draft. This process of iteration might occur 15-20 times as Beard develops his prose. A draft will then be sent to his agent, who may give some overview editorial comments within email, and comments that are more detailed provided within Microsoft Word. Beard then works through these to create a subsequent draft. The publishing editor then amends with further comments, until such a time as the final draft is sent to a copy editor. There are several layers of data that each address a part of Beard's process: emails, 
This is an accepted manuscript of an article published by Taylor \& Francis in Archives and Manuscripts on 12/8/2019, available online:

https://www.tandfonline.com/10.1080/01576895.2019.1608837.

word processing documents, notebooks, printed copies of drafts. They are not collated in an organised way, yet taken as a whole they form evidence of the creative process, and the broader networks of the creative industries, that facilitated the creation of the final text. Beard's archive thus provides a partial record of the creative process, spread across a variety of sources, through which a literary researcher may investigate the development of the work, and even read across the development of a number of works to explore developmental patterns.

By uncovering the respective creative practices of Alderman and Beard, and identifying the materials that evidence these practices, it becomes evident that creativity is a diverse practice by the preferences of individual authors, and their relationships with collaborators, publishing houses and editors. Uncovering the development of a creative work therefore involves tracing not just drafts, but also the broader networks that supported its production. There has been a tendency, among more traditional forms of archival research, to be concerned with the 'unravelling' of 'histories, temporalities, narratives, contingencies' attempting to investigate and discover hitherto unknown histories, to settle things once and for all, piecing together a clearer picture of what happened. ${ }^{42}$ However, the shift towards the archive-as-subject has encouraged scholars to revise the practices within their fields in light of the increased accessibility of archives, and to re-evaluate existing forms of criticism in light of the digital turn. For instance, the French tradition of 'genetic criticism,' informed by poststructural theorisation of the 'text' over the 'work', has approached archival materials in a quite different fashion that bears similarities to both archival studies and the digital humanities. ${ }^{43}$ Genetic criticism offers a surprising counter-narrative to any movement towards resolution, instead putting archives to work to open up the interpretive possibilities of the text/s.

In a move that extends Roland Barthes' proclamation that 'it is language which speaks, not the authors,' the genetic critic does not merely undermine the integrity of the work by reconceiving it as a text; rather he or she undermines its integrity by drawing attention to its different permutations in draft form. ${ }^{44}$ In doing so, a hive of possibilities is unearthed. The genetic critic refuses to think teleologically in terms of the correct timeline of drafts towards the finished work, instead, reading horizontally across the different archival surfaces. This is not about recovering authentic readings but engendering fresh routes through a literary text that unsettle the finished work. It uncovers buried traces that may have become 
This is an accepted manuscript of an article published by Taylor \& Francis in Archives and Manuscripts on 12/8/2019, available online:

https://www.tandfonline.com/10.1080/01576895.2019.1608837.

estranged to the work, as a psychoanalyst may root around in the unconscious of a patient. Ferrer and Groden refer to this as an 'esthetic of the possible' which returns the published work to the background of those potential versions that exist in the archive. ${ }^{45}$

The 'esthetic of the possible' has, though, been largely limited to the study of paper manuscripts by canonical authors, revolutionary as the approach may be. It is surprising to note that, in response to the shift of power from the author to the reader that this movement seems to take much further than Barthes ever did, the approach of the reader has in fact been quite conservative. If we were to think of genetic criticism in the digital context for a while, though, the synergies for research become evident. Taking into consideration all the possible activities that working with a computer might open up, it becomes evident that a major step shift can occur that allows a proliferation of possible interpretations of a particular set of archival materials. 'Play' is a word with a particular resonance with poststructuralism in mind. It implies an endless deferral of meaning and a creative way of seeking out possibility. We may find it useful to think of play as a guiding method in developing new methods of digital archiving, then, as something that might help us to explore the esthetic of the possible in new contexts.

These insights come at an opportune moment where researchers from the digital humanities are beginning to address similar issues by developing new theoretical and practical approaches to interface development and digital resource development. Here, the interface can be viewed as a mediating experience between the reader and the text, which thereby constitutes a user experience. As Johanna Drucker notes, we do not access data through a web page, but rather a web page is structured to support, and to influence, certain forms of interpretation for that data. ${ }^{46} \mathrm{~A}$ search box is not neutral, because it prioritises search-based discovery regardless of a user's own frame of reference. The interface codifies and confines the work that we do. If we accept this, we inevitably also accept that the interface is not neutral in its influence upon either the material or the reader. Every decision regarding interface development thus becomes an editorial decision that promotes one form of interpretation over another. ${ }^{47}$ Partiality and subjectivity are built into each position. ${ }^{48}$ However, just as genetic criticism offers an opportunity to think anew about archival research, this realisation offers an opportunity for us to think differently about how we create interfaces, as Mitchell Whitelaw argues: 
This is an accepted manuscript of an article published by Taylor \& Francis in Archives and Manuscripts on 12/8/2019, available online:

https://www.tandfonline.com/10.1080/01576895.2019.1608837.

Whether a command-line console or an immersive visualization, these collections come to us in specific, concrete form: and crucially that form is constructed and contingent. It can always be otherwise. ${ }^{49}$

In recent years, the digital humanities have expended significant effort to express the extent to which the development of digital tools and interfaces for work in the humanities can be considered scholarship. This emerged from a sense that DH had been relatively unsuccessful at expressing the ways in which its activities explore the 'big questions' of how they 'contribute to a larger shared agenda expressed in the conjunction and collision of many fields'. ${ }^{50}$ The response to the provocation that digital artefacts may need some measure of discourse to be considered knowledge led to the formation of a literature that addresses forms of building. This building, otherwise defined as 'coding' or 'programming' with the intention of creating useful computational tools for the humanities, can be understood as a form of scholarship in itself. Stephen Ramsay and Geoffrey Rockwell have argued that digital artefacts can be thought of as 'hermeneutical instruments through which we can interpret other phenomena', in other words, work undertaken to define and produce a prototype or a digital tool is intellectual work that can be considered a theoretical framework for interpretation..$^{51}$

Furthermore, Johanna Drucker and Bethany Nowviskie have noted that subjectivity offers an important counterpoint to the increasingly standardised nature of digital materials, computing systems, and workflows for computational analysis. Instead, they promote a 'speculative approach' to data that engages with subjective tools as a means of interpretation in computing environment. Underpinning this is the observation that 'most importantly, the speculative approach is premised on the idea that a work is constituted in an interpretation enacted by an interpreter, ${ }^{52}$ Despite this ambition, and the huge influence it has had upon infrastructure development, the hermeneutics of tool development are still to fully address how tools can also be situated within a particular disciplinary tradition. Highly innovative approaches to digital archiving have nevertheless been narrow in what of the author's digital footprint can be made available as evidence. Innovative as the emulation of Salman Rushdie's desktop computer environment was in technical terms, Benjamin Alexander, for instance, argues that access to the additional layers of evidence that we have discussed here would constitute a 'truly revolutionary' moment for literary studies. ${ }^{53}$ This is an important point: something that is technologically innovative may not constitute a revolutionary 
This is an accepted manuscript of an article published by Taylor \& Francis in Archives and Manuscripts on 12/8/2019, available online:

https://www.tandfonline.com/10.1080/01576895.2019.1608837.

moment for researchers; and indeed may not be appropriate to archivists in other circumstances. The possibilities of the digital archive, then, need to be addressed in direct relation to the contextual factors that can take both research and practice forward.

In this respect, we can begin to see a fruitful synergy emerge from the urge towards 'play' criticism, and the way that it might be addressed by developing theory-driven tools in the digital humanities. There is a productive interplay between the theories of play and interface: they both situate their objects of study as situated, partial, and subjective; they both support new interpretive frameworks for the archive that address the impulse to explore; and they imply a supporting impulse to break down existing infrastructures and rebuild them in a manner informed by humanistic critique. ${ }^{54}$ Hobbs furthermore argues that we need to understand the 'context, use, and writers' own understanding of their documents, as well as their intentions - whether realised or not - regarding the creation and dissemination of their work'. ${ }^{55}$ She emphasises the importance of working with living writers to understand the relationship between writers, their documentation, and their creative vision. In this way, collaboration between writers, archivists, and researchers can help to emphasise the intellectual genesis of writers' archives as subjects in their own right that drive interpretation of the interwoven network of potentialities that inform the creative text. We can now understand the digital archive not only as source, or as subject, but as computational data suited to new forms of interpretation. Winters notes that it is 'the portability of data, its separability from an easy-to-use but necessarily limiting interface, which underpins much of the most exciting work in the digital humanities'. ${ }^{56}$ In this case, it could be argued that it is through playing with data that we can loosen the grip of the original archival order, and free up the researcher to develop their own interpretive models. Through the complementary epistemologies of 'play' and 'building' we could see how Naomi Alderman's Skype calls directly influence her resultant writing; or we could explore the nature of change that occurs at each stage of Richard Beard's iterative editing cycle, to better understand the influence of his editors. The tools that develop through a focus on play can help us to reorder, reinterpret and remediate the archive in a myriad of non-destructive ways, at least in theory.

\section{The Humanistic Urge and the Archival Lens}

So how do these opportunities overlap in a way that might inform archival methods and tool development? And to what extent does this playfulness, this so-called 'jouer avec les fonds,' 
This is an accepted manuscript of an article published by Taylor \& Francis in Archives and Manuscripts on 12/8/2019, available online:

https://www.tandfonline.com/10.1080/01576895.2019.1608837.

translate to archival theory and practice? Several institutions have been successful in appraising, ${ }^{57}$ processing, ${ }^{58}$ and providing limited access to writers' digital archives ${ }^{59}$ These archivists are strong advocates for their materials, and drive awareness and reuse among their readers, but they must also work within legal and technical frameworks that affect their practice. As a result, the solutions they have adopted have been successful in processing digital materials, but are poorly aligned with the experimental, playful, research paradigms that such materials might support. It is here that collaboration between researchers and archivists is necessary to explore the 'horizons' of these collections, to identify where barriers are real, and to explore how they can be overcome in ways that safeguard creators and enhance research. The library sector has seen a call for increased openness and flexibility in the way that materials are purchased, digitised, and licensed. ${ }^{60}$ This approach has been understood in terms of 'generosity,' by approaching library collections as data that can be subjected to diverse interpretive frames:

A more generous interface would do more to represent the scale and richness of its collection. It would open the doors, tear down the drab lobby; instead of demanding a query it would offer multiple ways in, and support exploration as well as the focused enquiry where search excels. In revealing the complexity of digital collections, a generous interface would also enrich interpretation by revealing relationships and structures within a collection. ${ }^{61}$

From the archival perspective, though, the logic of speculative research, subjectivity in digital archives, and generosity in access arrangements, presents a direct challenge. Caswell argues that to archivists and archival scholars, archives are:

Collections of records, material and immaterial, the institutions that steward them, the places where they are physically located, the processes that designated them 'archival', 62

To the archivist, the materials of the writer's archive are never just literary, as they are inextricably linked to living or recently deceased individuals. In digital form, the number of individuals whose rights must be respected proliferates. Hobbs notes that the archivist must follow a series of processes including archival appraisal, acquisition, and arrangement and description. Each of these steps has a body of theory and practices attach that are to some extent standardised. ${ }^{63}$ As Pledge and Dickens describe in relation to the British Library's 
This is an accepted manuscript of an article published by Taylor \& Francis in Archives and Manuscripts on 12/8/2019, available online:

https://www.tandfonline.com/10.1080/01576895.2019.1608837.

Wendy Cope archive, the legal obligations placed upon UK institutions under the Data Protection Act 1998 make it essential to undertake sensitivity review of personal archives. The Cope archive contains a large corpus of email covering a period of seven years, and the British Library processed the dataset using ePADD. ${ }^{64}$ As a result, the BL was able to tag suitable messages for transfer to the reading rooms. This careful process of sensitivity review and standardisation of workflows, a necessary response to the large scale of digital archives, is nevertheless represented for users in the form of interfaces and tools that do not lend themselves to the kinds of experimentation within the fonds of the author's work that we describe in this article. The archival status of these materials requires the archivist to think not only in terms of what is possible, or of what is innovative and exciting, but in terms of how to manage archives in a way that simultaneously supports new interpretations, safeguards collections for future generations, and protects the privacy of living or recently deceased creators.

The idea of flattening archival strata to support playful, speculative approaches to displaying archival materials may therefore rely on an understanding of the archive that is in opposition to what can be achieved in practical terms. It may be, for instance, that a writer demands particular materials are redacted, or that a 'respect des fonds' requires a description that embeds a particular hierarchical interpretation upon the materials. However, a key affordance of digital media is that it can be rearranged, re-presented, and reordered without destroying the original materials, or their archival order. The challenge to the archivist, then, is to make the 'gesture that throws up the details of a life and the aesthetic direction of the author in a way that doesn't overwrite the myriad possibilities and spaces of archives'. ${ }^{65}$ This must sit beside an understanding on the part of researchers of the pressures and requirements that are placed upon the archivist. It must also include the author as an active participant, as a conscious creator of their archive and as a collaborator in playing within their own archive. Hobbs argues that we need to understand the 'context, use, and writers' own understanding of their documents, as well as their intentions - whether realized or not - regarding the creation and dissemination of their work'. ${ }^{66}$ She emphasises the importance of working with living writers to understand the relationship between writers, their documentation, and their creative vision. Archives of contemporary literary materials, such as the BACW, provide a fertile space for working through these issues. It is within these institutions that the opportunities for truly interdisciplinary collaboration and knowledge exchange emerge, represented in the co- 
This is an accepted manuscript of an article published by Taylor \& Francis in Archives and Manuscripts on 12/8/2019, available online:

https://www.tandfonline.com/10.1080/01576895.2019.1608837.

development of tools for digital forensic work that would support several modes of humanistic work. We have termed this non-destructive approach to archival representation 'jouer avec les fonds' to capture how it might combine the models of 'play' from genetic criticism and 'building' from digital humanities into the creation of flexible tools for processing and reinterpretation of literary archives that might in time, through collaborative exploration of complex archival challenges, support both archival practice and digital scholarship.

\section{Conclusion}

The Humanities research we discuss here is subjective and speculative in nature, while archival practice relies upon standardisation, establishing workflows, and following strict regulations and guidelines. And yet, the archivist is always already involved in a process of mediation between the, no doubt, at times, eccentric order of the archive as it is received from the author and the order it must achieve to meet institutional, and even global, standards of cataloguing. The objectives of the speculative researcher and of the institutional archivist might pull in different directions then, but capacity for more flexible states of order within the digital archive certainly mitigates against this pull. This flexibility requires new forms of collaboration to emerge between writers, archivists and researchers; writers can be invited to take part in this collaborative and speculative work, both the play and the building. In doing so, each party becomes a proactive participant in providing interpretation and shape to the 'archive-as-subject,' in a non-destructive way that opens up new forms of analysis and creativity.

We have argued in this article that the design of interfaces and tools can be understood as a way to explore areas the shifting affordances of digital objects are open to new forms of interpretation, and new forms of archival practice. This requires archivists and researchers to address digital tools as an additional layer for interpretation and analysis; in other words, the contexts for creation and analysis of digital archival materials both fall within the horizons of our analysis. Perhaps one model for collaboration would be to focus on establishing a relationship to the archives that Kastner describes as 'traceable, self-conscious, and open' ${ }^{67}$ Our model for engagement with the archive thereby becomes one of recording: recording the author's intention for their archive; recording the archivist's relationship to forming and defining the archives that they curate; recording the researcher's epistemological 
This is an accepted manuscript of an article published by Taylor \& Francis in Archives and Manuscripts on 12/8/2019, available online:

https://www.tandfonline.com/10.1080/01576895.2019.1608837.

and methodological approach to the archives; and finally engaging in collaborative

experimentation that seeks to open up new forms of recording. We propose, therefore, that future work should concentrate on practical case studies that unpack the working practices of writers from the perspective of both researchers and archivists, in order to situate the archive in an ongoing dialogue between authors, archivists, and their users. Such an approach would support the development of tools that address the needs and intellectual roots of these three very different ways of working.

Just as 'building' for a digital humanities scholar is understood as a form of practiceled inquiry and research, we expect the process of dialogue between author, archivist and researcher to produce new ways of archiving and new ways of using archives that are sensitive to both the limitations and opportunities felt by all parties involved. In the long term, we hope that this work will begin to more clearly demarcate, populate and expand the horizon of the digital archive in a way that takes all stakeholders forward together. 
This is an accepted manuscript of an article published by Taylor \& Francis in Archives and Manuscripts on 12/8/2019, available online:

https://www.tandfonline.com/10.1080/01576895.2019.1608837.

\footnotetext{
${ }^{1}$ Lisa Stead, 'Introduction,' in Lisa Stead \& Carrie Smith (eds.), The Boundaries of the Literary Archive, Ashgate, London, 2013, pp. 1-15.

2 Ibid. p. 1.

${ }^{3}$ Michelle Caswell, "The Archive' Is Not an Archives: On Acknowledging the Intellectual Contributions of Archival Studies,' Reconstruction: Studies in Contemporary Culture, vol. 16, no. 1, 2016, available at https://escholarship.org/uc/item/7bn4v1fk, accessed 10 September 2018.

${ }^{4}$ Matthew G. Kirschenbaum, Mechanisms: New Media and the Forensic Imagination, MIT Press, Boston, MA, 2008.

${ }^{5}$ Matthew Kirschenbaum, 'The .txtual Condition: Digital Humanities, Born-Digital Archives, and the Future Literary,' Digital Humanities Quarterly, vol. 7, no. 1, 2013, available at http://www.digitalhumanities.org/dhq/vol/7/1/000151/000151.html, accessed 15 November 2018.

${ }^{6}$ Johann Drucker, 'Performative Materiality and Theoretical Approaches to Interface,' Digital Humanities Quarterly, vol. 7, no. 1, 2013, available at http://www.digitalhumanities.org/dhq/vol/7/1/000143/000143.html, accessed 26 November 2018.

${ }^{7}$ Stephen Ramsay \& Geoffrey Rockwell, 'Developing Things: Notes toward an Epistemology of Building in the Digital Humanities,' in Debates in the Digital Humanities, University of Minnesota Press, Minneapolis MN, 2012.

${ }^{8}$ Michel Contat, Denis Hollier \& Jacques Neefs, 'Drafts,' Yale French Studies, vol. 89, 1996.

${ }^{9}$ S. Muller, J.A. Feith \& R. Fruin, Manual for the Arrangement and Description of Archives, trans. Arthur H. Leavitt, 2nd edn, Society of American Archivists, Chicago, 2003, p. 54.

${ }^{10}$ Jennifer Douglas, 'Original Order, Added Value? Archival Theory and the Douglas Coupland Fonds,' in Carrie Smith \& Lisa Stead (eds), The Boundaries of the Literary Archive, Ashgate, London, 2013, pp. 45-55. 11 ibid. pp. 54-55.

${ }^{12}$ Further details of which can be found online at https://portal.uea.ac.uk/library/archives/bacw.
}

13 A full list of authors for which the archive holds collections is available here: https://portal.uea.ac.uk/library/archives/bacw/authors.

${ }^{14}$ Salman Rushdie's archive, for instance, was acquired by Emory University Library in 2006, while the Harry Ransom Center at the University of Texas acquired Ian McEwan's archive in 2014 for a reported $\$ 2 \mathrm{~m}$.

${ }^{15}$ British Archive for Contemporary Writing, FAQ For Authors Depositing Within the Storehouse of the British Archive for Contemporary Writing, n.d., https://portal.uea.ac.uk/documents/6207125/9157971/FAQ+-

+ The + Storehouse + British + Archive+for+Contemporary+Writing/ee13a4db-1f46-43fe-9ae2-69906d31a23b, accessed 27 November 2018.

${ }^{16}$ Victoria Sloyan, "Born-Digital Archives at the Wellcome Library: Appraisal and Sensitivity Review of Two Hard Drives," Archives and Records: The Journal of the Archives and Records Association, vol. 37, no. 1, 2016, pp. 20-36.

${ }^{17}$ Jonathan Pledge \& Eleanor Dickens, 'Process and Progress: Working with Born-Digital Material in the Wendy Cope Archive at the British Library,' Archives and Manuscripts, vol. 46, no. 1, 2018, pp. 59-69.

${ }^{18}$ Elain Justice, A World Mapped by Stories: The Salman Rushdie Archive, Emory Libraries and Information technology, 2010, available at http://web.library.emory.edu/news-events/news/archives/2010/world-mappedstories-salman-rushdie-archive-through-sept-26-2010-0.html

${ }^{19}$ Dorothy Waugh, Elizabeth Russey Roke \& Erika Farr, 'Flexible processing and diverse collections: a tiered approach to delivering born digital archives,' Archives and Records, vol. 37, no. 1, 2016, pp. 3-19.

${ }^{20}$ DROID (Digital Record Object Identification) is a free file profiling tool developed by the UK National Archives. It produces a range of metadata relating to born-digital records, including filenames, file formats, last modified dates, and extensions.

${ }^{21}$ Sloyan, 'Born-Digital Archives at the Wellcome Library: Appraisal and Sensitivity Review of Two Hard Drives,' p. 30.

22 ibid. p. 22.

${ }^{23}$ Terry Cook, "We Are What We Keep; We Keep What We Are': Archival Appraisal Past, Present and Future,' Journal of the Society of Archivists, vol. 32, no. 2, 2011, pp. 173-189.

${ }^{24}$ Catherine Hobbs \& Sarah Kastner, 'Literary Archives, Fictional Truths and Material(real)ities: The Yvonne Vera Project - Catherine Hobbs and Sarah Kastner,' 2014, available at http://nomorepotlucks.org/site/literaryarchives-fictional-truths-and-materialrealities-the-yvonne-vera-project-catherine-hobbs-and-sarah-kastner/, accessed 5 November 2018.

${ }^{25}$ Kirschenbaum, 'The .txtual Condition: Digital Humanities, Born-Digital Archives, and the Future Literary.' 
This is an accepted manuscript of an article published by Taylor \& Francis in Archives and Manuscripts on 12/8/2019, available online:

https://www.tandfonline.com/10.1080/01576895.2019.1608837.

${ }^{26}$ Terry Cook, 'Remembering the Future: Apprasial of Records and the Role of Archives in Constructing Social Memory,' in Archives, Documentation, and Institutions of Social Memory: Essays from the Sawyer Seminar, University of Michigan Press, Ann Arbor, 2006, p. 170.

${ }^{27}$ Caswell, "The Archive' Is Not an Archives: On Acknowledging the Intellectual Contributions of Archival Studies.'

${ }^{28}$ Johanna Drucker, 'Humanities Approaches to Interface Theory,' Culture Machine, vol. 12, 2011.

${ }^{29}$ Kyle Jensen, Reimagining Process: Online Writing Archives and the Future of Writing Studies, Southern

Illinois University Press, Carbondale, IL, 2015.

${ }^{30}$ Justice.

${ }^{31}$ Drucker, 'Performative Materiality and Theoretical Approaches to Interface.'

${ }^{32}$ Sloyan, 'Born-Digital Archives at the Wellcome Library: Appraisal and Sensitivity Review of Two Hard Drives,' pp. 31-32.

${ }^{33}$ Jonathan Pledge \& Eleanor Dickens, 'Process and Progress: Working with Born-Digital Material in the Wendy Cope Archive at the British Library,' Archives and Manuscripts, vol. 46, no. 1, 2018, pp. 59-69, p. 67.

${ }^{34}$ Jane Winters, 'Coda: Web Archives for Humanities Research - Some Reflections,' in The Web as History, UCL Press, London, 2017, pp. 238-248, p. 246.

${ }^{35}$ Ramsay \& Rockwell, 'Developing Things: Notes toward an Epistemology of Building in the Digital Humanities.'

${ }^{36}$ Ann Laura Stoler, 'Colonial archives and the arts of governance,' Archival Science, vol. 2, no. 1-2, 2002, p. 93.

37 Further information on her work and archive is available from the BACW at https://portal.uea.ac.uk/library/archives/bacw/alderman.

38 The Diasporic Literary Archives Network was established by the University of Reading in 2012 to better understand the political, commercial and technological issues of authors' literary archives. Further information can be found at http://www.diasporicarchives.com/.

${ }^{39}$ Authors and their Papers: A Guidance Sheet for Authors and Writers, 2014.

${ }^{40}$ Vintage is an imprint of large commercial publisher Penguin Random House.

${ }^{41}$ Lee Rourke, 'Why Creative Writing is Better with a Pen,' The Guardian, March 11, 2011, available at https://www.theguardian.com/books/2011/nov/03/creative-writing-better-pen-longhand, accessed 11 December 2018.

${ }^{42}$ Anita Helle, The Unraveling Archive: Essays on Sylvia Plath, Anita Helle (ed.), University of Michigan Press, Ann Arbor, MI, 2007, p. 1.

${ }^{43}$ Jed Deppman, Daniel Ferrer \& Michael Groden, Genetic Criticism: Texts and Avant-textes, University of Pennsylvania Press, Philadelphia, PA, 2004.

${ }^{44}$ Roland Barthes, 'The death of the author,' trans. Stephen Heath, in Image-Music-Text, Fontana Press, London, 1977, p. 126.

${ }^{45}$ Daniel Ferrer \& Michael Groden, Genetic Criticism: Texts and Avant-Textes, Jed Deppman, Daniel Ferrer \& Michael Groden (eds), University of Pennsylvania Press, Philadelphia, PA, 2004, p. 6.

${ }^{46}$ Drucker, 'Performative Materiality and Theoretical Approaches to Interface.'

${ }^{47}$ [reference removed to protect authorial anonymity]

${ }^{48}$ Donna Haraway, 'Situated Knowledges: The Science Question in Feminism and the Privilege of Partial Perspective,' Feminist Studies, vol. 14, no. 3, 1988, pp. 575-599.

${ }^{49}$ Mitchell Whitelaw, 'Generous Interfaces for Digital Cultural Collections,' Digital Humanities Quarterly, vol.

9, no. 1, 2015, available at http://www.digitalhumanities.org/dhq/vol/9/1/000205/000205.html, accessed 18 November 2018.

${ }^{50}$ Alan Liu, 'Is Digital Humanities a Field? - An Answer From the Point of View of Language,' Alan Liu, 2013.

${ }^{51}$ Stephen Ramsay \& Geoffrey Rockwell, 'Developing Things: Notes toward an Epistemology of Building in the Digital Humanities.'

52 Johanna Drucker \& Bethany Nowviskie, 'Speculative Computing: Aesthetic Provocations in Humanities Computing,' in Susan Schreibman, Ray Siemens \& John Unsworth (eds), Companion to Digital Humanities, Hardcover, Blackwell Companions to Literature and Culture, Blackwell Publishing Professional, Oxford, 2004.

${ }^{53}$ Benjamin Alexander, 'The Salman Rushdie Archive and the Re-Imagining of a Philological E-volutin,' in Texts, Transmissions, Receptions, Radboud Studies in Humanities, Koninklijke Brill, Leiden, 2015, available at https://doi.org/10.1163/9789004270848_006, accessed 4 January 2018. p. 75.

${ }^{54}$ Susan Brown, Tanya Clement, Laura Mandell, Deb Verhoeven \& Jacque Wernimont, 'Creating Feminist Infrastructures in the Digital Humanities,' paper presented at Digital Humanities 2016, Krakow, 2016, available at http://dh2016.adho.org/abstracts/233, accessed 14 December 2018.

${ }^{55}$ Catherine Hobbs, 'New Approaches to Canadian Literary Archives,' Journal of Canadian Studies/Revue d'études canadiennes, vol. 40, no. 2, 2006, p. 113. 
This is an accepted manuscript of an article published by Taylor \& Francis in Archives and Manuscripts on 12/8/2019, available online:

https://www.tandfonline.com/10.1080/01576895.2019.1608837.

${ }^{56}$ Winters, 'Coda: Web Archives for Humanities Research - Some Reflections,' p. 246.

${ }^{57}$ Sloyan, 'Born-Digital Archives at the Wellcome Library: Appraisal and Sensitivity Review of Two Hard Drives.'

${ }^{58}$ Waugh et al., 'Flexible processing and diverse collections.'

${ }^{59}$ Pledge \& Dickens, 'Process and Progress: Working with Born-Digital Material in the Wendy Cope Archive at the British Library.'

${ }^{60}$ [reference removed to protect authorial anonymity]

${ }^{61}$ Whitelaw, 'Generous Interfaces for Digital Cultural Collections.'

${ }^{62}$ Caswell, "The Archive' Is Not an Archives: On Acknowledging the Intellectual Contributions of Archival Studies.'

${ }^{63}$ Hobbs \& Kastner, 'nomorepotlucks » Literary Archives, Fictional Truths and Material(real)ities.'

${ }^{64} \mathrm{ePADD}$ is a free, open source software package that supports the appraisal, processing, preservation, discovery, and delivery of historical email archives. It was developed by a collaborative team including Stanford University Libraries, Harvard University, The Metropolitan New York Library Council, the University of Illinois at UrbanaChampaign, and the University of California, Irvine.

${ }^{65}$ Ibid.

${ }^{66}$ Catherine Hobbs, 'New Approaches to Canadian Literary Archives,' Journal of Canadian Studies/Revue d'études canadiennes, vol. 40, no. 2, 2006, p. 113.

${ }^{67}$ Ibid. 